Original Article

\title{
Trends in Cigarette Use Behaviors Among Adolescents by Region in Korea
}

\author{
Nam Soo Hong ${ }^{1}$, Keon Yeop Kim ${ }^{1}$, Soon-Woo Park ${ }^{2}$,Jong-Yeon Kim² ${ }^{2}$ Jisuk Bae ${ }^{2}$,Won Kee Lee ${ }^{1 *}, K_{\text {Ki Su Kim }}^{1}$ \\ 'Department of Preventive Medicine, School of Medicine, Kyungpook National University; \\ ${ }^{2}$ Department of Preventive Medicine, Catholic University of Daegu School of Medicine, Daegu, Korea
}

\begin{abstract}
Objectives: Understanding recent trends in cigarette smoking among adolescents is important in order to develop strategies to prevent cigarette smoking. The aim of this study was to compare recent trends in cigarette smoking for adolescents living in rural areas, small towns and metropolitan cities in Korea.

Methods: The raw data from the Korea Youth Risk Behavior Web-based Survey (KYRBWS) from 2005 to 2009 were used. Data were analyzed by using the method of complex survey data analysis considering complex sampling design. Logistic regression models were used to evaluate significant linear time trends in cigarette smoking. The indicators of cigarette use behaviors were 'current smoking rate', 'frequent smoking rate', 'heavy smoking rate' and 'smoking experience rate before 13 years of age'. All analyses were conducted according to gender.

Results: Statistically significant increasing trends in current smoking rate and frequent smoking rate were observed and borderline significant increasing trends in heavy smoking rate were shown among rural boys. Among metropolitan city boys, statistically significant increasing trends were also seen for frequent smoking. Statistically significant decreasing trends in current smoking rate were observed among small town and metropolitan city girls. Smoking experience rate before 13 years of age for rural girls decreased significantly.

Conclusions: Cigarette smoking prevalence among adolescents in the rural areas has increased in the last five years especially among boys. Our findings suggest that anti-tobacco program for adolescents should be conducted primarily for those in rural areas.
\end{abstract}

Key words: Smoking, Trends, Adolescent, Rural health, Korea Youth Risk Behavior Web-based Survey (KYRBWS) J Prev Med Public Health 2011;44(4):176-184

\section{INTRODUCTION}

It is widely known that smoking is an important risk factor associated with several diseases and death. According to World Health Organization (WHO), more than five million people have died every year due to the smoking-related diseases worldwide, and if this trend continues at this pace, more than eight million people worldwide are expected to die every year due to smoking in 2030 [1].

In particular, the effect of smoking on adolescents outweighs that on adults. It is more common for the adolescents who smoke daily to have physical symptoms such as headache, cough, abdominal pain, and sleeping problem compared to non-smoking adolescents [2]. In addition, as the cell division in the lungs is active in adolescence, the tobacco toxins affect cell division, increasing the carcinogenicity. Furthermore, the adolescents who started smoking earlier have higher

(10) This is an Open Access article distributed under the terms of the Creative Commons Attribution Non-Commercial License (http://creativecommons.org/licenses/by-nc/3.0/) which permits unrestricted non-commercial use, distribution, and reproduction in any medium, provided the original work is properly cited. chance of DNA damage risk, which increases the probability of lung cancer development in the future when they become adults [3]. In addition to the influence on physical health, adolescent smoking has been known to be highly relevant to the use of alcohol or other drugs, dangerous sexual behaviors, and violence by affecting mental health [4]. It is also reported that experiencing or starting smoking during adolescence can lead to smoking in adulthood, indicating that the smoking habits formed in adolescence are not easy to be corrected [5]. Therefore, attentions and efforts should be made for the smoking prevention and cessation of adolescents at the national level.

Meanwhile, even though the overall public health status has improved, there still exists health status difference among regions [6]. Several studies on the difference of health status in the communities have reported that the socio-environmental nature is related to the individual health status. Robert [7] reported that not

Corresponding author : Keon Yeop Kim, MD, PhD

101 Dongin 2, Jung-gu, Daegu, Korea

Tel : +82-53-420-4863, Fax: +82-53-425-2447, E-mail : pmkky@knu.ac.kr

Received : 10 January 2011, Accepted : 16 May 2011

*Current affiliation: Office of Medical Education, School of Medicine, Kyungpook National University, Daegu, Korea 
only the socio-economic status of individuals and families, but also that of communities influences the health status of individuals. In addition, Kim and Lee [6] reported that the mortality and the causes of death vary depending on the ecological environment of the regions (metropolitan city, small town, rural areas, mountainous areas and coastal areas).

According to the researches in Korea, the income disparity between the urban and rural areas has been expanding rapidly since the mid-1990s, and this has resulted in the increased disparity across all sectors of society including healthcare, transportation, communications, education, and culture [8]. In a situation where the inequality between the urban and rural areas exists and the gap is widening, there might be difference in the health status and health behavior of adolescents between the urban and rural areas, given that the socioenvironmental status of the communities is related to the health status.

The studies in Korea found that the smoking rate of rural high school students is higher than that of urban high school students [9]. In addition, an analysis of indicators of adolescent smoking in metropolitan cities, small towns and rural areas showed that the smoking experience rate and smoking experience rate before 13 years of age for rural areas are significantly higher than those for urban areas [10]. However, the studies in Korea so far have limitations in that they have compared the smoking rate between the urban and rural areas on a cross-sectional basis. While several studies on the smoking trend of adolescents in urban and rural areas have been reported in other countries [11-13], there is no study on the trend of indicators of adolescent smoking in urban and rural areas in Korea.

This study, therefore, aims to compare the trend of indicators of adolescent smoking by dividing the regions into metropolitan cities, small towns and rural areas. It also provides the basic information to set the policy direction of smoking prevention and cessation for the adolescents by comparing the trend of smoking indicators by region.

\section{METHODS}

\section{Study Subjects}

In this study, the raw data from the Korea Youth Risk Behavior Web-based Survey (KYRBWS) for 5 years from 2005 to 2009 were used. The KYRBWS first grouped the City, Gun, and $\mathrm{Gu}$ within the 16 provinces into metropolitan cities, small towns and rural areas, and subdivided them into strata using detailed regional groups and schools (middle school, general high school, and vocational high school) as a stratification variable, and then set the school as a primary sampling unit, and the division as a secondary sampling unit, using twostage cluster sampling. The survey was conducted for approximately 65000 students from the first grade of middle school to the second grade of high school in 2005, which is the first survey year, and for approximately 80000 students from the first grade of middle school to the third grade of high school from 2006 to 2009 every year. Participation rates for each survey year from 2005 to 2009 were $89.7 \%$, 90.9\%, $94.8 \%, 95.1 \%$, and $97.6 \%$, respectively [14].

\section{Study Methods}

The KYRBWS was conducted in a self-administered online survey with guaranteed anonymity in the school computer lab, where the internet was connected. As a means of conducting the survey, email was used in 2005, and the certificate number was used from 2006.

When selecting smoking indicators, two factors were considered: the availability of analyzing the 5 year trend considering the degree of changes in the questioning methods and the contents of the questionnaire items; and the representativeness that can identify the current smoking status of adolescents including whether they are currently smoking or not, smoking frequency, amount of smoking, and the time of first exposure to smoking. Based on these consideration, four indicators - 'current smoking rate', 'smoking rate of more than 20 days a month', 'smoking rate of more than 10 cigarettes a day', and 'smoking experience rate before 13 years of age' were selected and analyzed.

'Current smoking rate' represents the proportion of current smokers among all subjects, and 'smoking rate of more than 20 days a month' represents the proportion of the frequent smokers among the adolescents. 'Smoking rate of more than 10 cigarettes a day' is the indicator for heavy adolescent smoker [15]. 'Smoking experience rate before 13 years of age' is the indicator of the adolescents who have experienced smoking in their early ages.

Each indicator was defined as follow: 'current smoking rate' is the percentage of students who smoked cigarettes on one or more of the past 30 days; 'smoking rate of more than 20 days a month' is the percentage of students who smoked cigarettes on 20 or more of the past 30 days; 'smoking rate of more than 10 cigarettes a 
Table 1. Distribution of study participants by region, survey year and sex

\begin{tabular}{|c|c|c|c|c|c|}
\hline Year & Sex & Rural area & Small town & Metropolitan city & Total \\
\hline \multirow[t]{3}{*}{2005} & Male & $4465(8.0)$ & 9877 (39.2) & $15532(52.8)$ & $29874(100.0)$ \\
\hline & Female & $4230(8.0)$ & $9838(39.6)$ & $14282(52.4)$ & $28350(100.0)$ \\
\hline & Subtotal & $8695(8.0)$ & $19715(39.4)$ & 29814 (52.6) & $58224(100.0)$ \\
\hline \multirow[t]{3}{*}{2006} & Male & $5590(8.1)$ & $12224(39.8)$ & 19390 (52.2) & $37204(100.0)$ \\
\hline & Female & $5105(7.9)$ & $11981(40.4)$ & $17114(51.7)$ & $34200(100.0)$ \\
\hline & Subtotal & $10695(8.0)$ & $24205(40.1)$ & 36504 (51.9) & 71404 (100.0) \\
\hline \multirow[t]{3}{*}{2007} & Male & $5658(6.6)$ & 13497 (41.8) & 20311 (51.6) & $39466(100.0)$ \\
\hline & Female & $4788(6.5)$ & $12172(42.2)$ & $18272(51.3)$ & $35232(100.0)$ \\
\hline & Subtotal & $10446(6.5)$ & 25669 (42.0) & $38583(51.5)$ & $74698(100.0)$ \\
\hline \multirow[t]{3}{*}{2008} & Male & $4926(5.4)$ & $13722(39.4)$ & 20630 (55.2) & $39278(100.0)$ \\
\hline & Female & 4521 (5.3) & $12775(39.7)$ & 18664 (55.0) & $35960(100.0)$ \\
\hline & Subtotal & $9447(5.4)$ & 26497 (39.5) & $39294(55.1)$ & 75238 (100.0) \\
\hline \multirow[t]{3}{*}{2009} & Male & $4796(5.4)$ & 13802 (39.9) & 21014 (54.7) & $39612(100.0)$ \\
\hline & Female & 4576 (5.3) & 12605 (40.2) & $18273(54.5)$ & 35454 (100.0) \\
\hline & Subtotal & $9372(5.3)$ & $26407(40.0)$ & 39287 (54.6) & 75066 (100.0) \\
\hline Total & & $48655(6.6)$ & $122493(40.2)$ & $183482(53.2)$ & $354630(100.0)$ \\
\hline
\end{tabular}

day' is defined for the period between 2005 and 2008 as the percentage of students who smoked more than 10 cigarettes per day on the days they smoked during the past 30 days, and for 2009, it is defined as the percentage of students who smoked more than 10 cigarettes a day on average during the past 30 days. 'Smoking experience rate before 13 years of age' is defined as the percentage of students who smoked cigarette for the first time before 13 years of age [14].

The trend of four smoking indicators was compared according to the size of residing areas. The residing areas were divided into three regions and analyzed according to the sampling frame of the KYRBWS, which was stratified by classifying the population into metropolitan cities, small towns and rural areas.

\section{Data Analysis}

The KYRBWS was designed as a complex sample, and a complex survey data analysis considering stratification, cluster, weight, etc. was employed in its analysis. For the analysis of yearly trend, the smoking indicators were analyzed with logistic regression by setting the time variables as independent variable and smoking indicators as the dependent variable to see if the smoking indicators have the form of a linear trend. Since smoking indicators were significantly different in their distribution between male and female, all analyses were performed by stratifying them into male students and female student. In addition, as they became higher grade, they could not recall exactly when they first smoked, so the 'smoking experience rate before 13 years of age' was analyzed only for the first grade students of middle school. Furthermore, because the third grade students of high school were excluded from the first survey, the analysis was made by adjusting grade. All statistical analyses were performed using SAS version 9.2 (SAS Inc., Cary, NC, USA), and the significance test was carried out at $\mathrm{p}<0.05$, and $\mathrm{p}$ values between 0.05 and 0.1 were considered as the borderline level of significance.

\section{RESULTS}

The distribution of the subjects by region, year, and gender is shown in Table 1. The total number of subjects residing in rural areas for 5 years was 48655 (6.6\%), that in small towns was $122493(40.2 \%)$, and that in metropolitan cities was 183482 (53.2\%), showing that the proportion of students residing in metropolitan cities was the highest.

The annual figures of smoking indicators for each region and $95 \%$ confidence interval are presented in Table 2, and diagrammed in Figure 1 and Figure 2. The result of logistic regression, which was adjusted for grade to analyze the trend of adolescent smoking indicators, is shown in Table 3.

'Current smoking rate' of male students in rural areas showed a trend of significant increase from $16.1 \%$ in 2005 to $21.6 \%$ in 2009 ( $p=0.009)$, whereas the male students of small towns and metropolitan cities and female students in rural areas did not show a statistically significant trend. The current smoking rate of female students in small towns has significantly decreased from $9.5 \%$ in 2005 to $7.5 \%$ in 2009 ( $p=0.001)$, and that of female students in metropolitan cities also decreased significantly from $8.5 \%$ in 2005 to $7.5 \%$ in 2009 
Table 2. Prevalence and 95\% confidence interval of indicators of smoking by region, survey year and sex

\begin{tabular}{|c|c|c|c|c|}
\hline & $\begin{array}{c}\text { Current } \\
\text { smoking rate }^{1}\end{array}$ & $\begin{array}{c}\text { Frequent } \\
\text { smoking rate }^{2}\end{array}$ & $\begin{array}{c}\text { Heavy } \\
\text { smoking rate }^{3}\end{array}$ & $\begin{array}{l}\text { Smoking experience rate } \\
\text { before } 13 \text { years of age }{ }^{4}\end{array}$ \\
\hline \multicolumn{5}{|l|}{ Male } \\
\hline \multicolumn{5}{|c|}{ Rural area } \\
\hline 2005 & $16.1(14.1-18.1)$ & $7.3(5.7$ - 8.9) & $3.1(2.1-4.0)$ & $20.8(17.8$ - 23.8) \\
\hline 2006 & $15.9(13.7-18.0)$ & $8.2(6.5$ - 9.9) & $3.9(2.9-4.9)$ & $17.0(13.3-20.8)$ \\
\hline 2007 & $19.3(16.4-22.2)$ & $11.3(9.3-13.4)$ & $5.6(4.3-6.8)$ & $17.6(14.1-21.2)$ \\
\hline 2008 & $21.6(18.2-25.1)$ & $13.4(10.5$ - 16.4) & $6.2(4.6-7.8)$ & $18.4(14.8-22.1)$ \\
\hline 2009 & $21.6(17.6-25.6)$ & $14.5(11.2$ - 17.9) & $5.3(3.4-7.1)$ & $17.9(15.2-20.6)$ \\
\hline \multicolumn{5}{|c|}{ Small town } \\
\hline 2005 & $14.7(13.0-16.3)$ & $6.5(5.3-7.8)$ & $2.7(2.0-3.4)$ & $14.8(12.9-16.7)$ \\
\hline 2006 & $17.1(15.0$ - 19.3) & $9.3(7.6-11.0)$ & $4.8(3.9-5.8)$ & $13.2(10.7-15.7)$ \\
\hline 2007 & $18.7(16.7$ - 20.6) & $11.0(9.2-12.8)$ & $4.7(3.7-5.6)$ & $13.4(11.6$ - 15.3) \\
\hline 2008 & $16.9(15.1-18.6)$ & $10.4(8.9-12.0)$ & $3.5(2.8-4.1)$ & $12.9(10.9-14.8)$ \\
\hline 2009 & $17.3(15.5-19.1)$ & $10.7(9.1-12.3)$ & $3.8(3.1-4.5)$ & $12.7(10.6-14.7)$ \\
\hline \multicolumn{5}{|c|}{ Metropolitan city } \\
\hline 2005 & $13.8(12.6-15.0)$ & $6.4(5.5-7.3)$ & $3.0(2.5-3.5)$ & $14.7(12.9-16.4)$ \\
\hline 2006 & $15.1(13.9-16.4)$ & $8.0(7.0-9.0)$ & $3.6(3.0-4.1)$ & $11.6(10.1$ - 13.2) \\
\hline 2007 & $16.1(14.9-17.2)$ & $9.1(8.0-10.1)$ & $4.0(3.4-4.5)$ & $12.8(11.5-14.2)$ \\
\hline 2008 & $16.3(14.9-17.7)$ & $10.6(9.4-11.8)$ & $4.2(3.6-4.8)$ & $12.9(11.5-14.2)$ \\
\hline 2009 & $17.1(15.7$ - 18.6) & $11.1(9.8-12.4)$ & $4.4(3.7-5.0)$ & $11.6(10.2-12.9)$ \\
\hline \multicolumn{5}{|c|}{ Female } \\
\hline \multicolumn{5}{|c|}{ Rural area } \\
\hline 2005 & $8.9(7.3-10.4)$ & $2.7(1.8$ - 3.6) & $0.9(0.4-1.3)$ & $12.0(9.2-14.8)$ \\
\hline 2006 & $9.2(7.3-11.1)$ & $3.6(2.3-4.9)$ & $1.3(0.7-2.0)$ & $7.5(5.4-9.5)$ \\
\hline 2007 & $10.2(7.9-12.5)$ & $5.4(3.5-7.4)$ & $2.1(1.1-3.2)$ & $9.9(7.0-12.8)$ \\
\hline 2008 & $9.1(7.3-10.8)$ & $4.4(3.2-5.5)$ & $1.2(0.7-1.7)$ & $8.6(6.4-10.8)$ \\
\hline 2009 & $8.8(6.7-10.8)$ & $4.6(3.2-6.1)$ & $1.1(0.7-1.5)$ & $6.9(4.8-9.1)$ \\
\hline \multicolumn{5}{|c|}{ Small town } \\
\hline 2005 & $9.5(8.3-10.7)$ & $3.5(2.6-4.3)$ & $1.1(0.8-1.5)$ & $10.2(8.4-12.1)$ \\
\hline 2006 & $9.3(7.8-10.8)$ & $4.1(3.1-5.2)$ & $1.6(1.0-2.1)$ & 7.5 (5.9 - 9.2) \\
\hline 2007 & $8.6(7.5-9.7)$ & $3.6(2.9-4.3)$ & $1.3(1.0-1.7)$ & $8.9(7.4-10.5)$ \\
\hline 2008 & $8.2(6.9-9.6)$ & $4.3(3.3-5.3)$ & $1.2(0.8-1.6)$ & $8.4(7.0$ - 9.8) \\
\hline 2009 & $7.6(6.4$ - 8.8) & $3.8(3.0-4.7)$ & $1.3(0.9-1.8)$ & $10.2(8.1$ - 12.2) \\
\hline \multicolumn{5}{|c|}{ Metropolitan city } \\
\hline 2005 & $8.5(7.5$ - 9.5) & $3.2(2.5$ - 3.8) & $1.4(1.0-1.7)$ & $10.3(9.0-11.5)$ \\
\hline 2006 & $9.0(7.7-10.3)$ & $4.3(3.4-5.3)$ & $1.7(1.2-2.2)$ & $8.9(7.8-10.1)$ \\
\hline 2007 & $8.8(7.6-10.0)$ & $4.1(3.3-5.0)$ & $1.4(1.1-1.7)$ & $9.2(7.9-10.5)$ \\
\hline 2008 & $8.0(6.9-9.2)$ & $4.6(3.6-5.5)$ & $1.5(1.2-1.9)$ & $9.6(8.5$ - 10.8) \\
\hline 2009 & $7.5(6.5$ - 8.6) & $4.0(3.2-4.8)$ & $1.6(1.2-1.9)$ & $8.1(6.9-9.2)$ \\
\hline
\end{tabular}

${ }^{1}$ Percentage of students who smoked cigarettes on one or more of the past 30 days.

${ }^{2}$ Percentage of students who smoked cigarettes on 20 or more of the past 30 days.

${ }^{3}$ Percentage of students who smoked more than 10 cigarettes per day on the days they smoked during the past 30 days.

${ }^{4}$ Percentage of students who smoked cigarette for the first time before 13 years of age among 1 st grade of middle school students.

$(\mathrm{p}=0.007)$.

'Smoking rate of more than 20 days a month' showed a trend of significant increase in the male students in rural areas from $7.3 \%$ in 2005 to $14.5 \%$ in 2009 (p $<0.001$ ), and that of male students in metropolitan cities also showed a significantly increasing trend from $6.4 \%$ in 2005 to $11.1 \%$ in 2009 . The regression coefficient of rural areas was 0.154 and that of metropolitan cities was 0.092 , indicating that the male students in rural areas showed more steeply increasing trend. The female students did not show a statistically significant trend in all three regions.

Although there was no group showing a statistically significant trend in the 'smoking rate of more than 10 cigarettes a day', the male students in rural areas showed an increasing trend at a borderline significance level from $3.1 \%$ in 2005 to $6.2 \%$ in 2008 and to $5.3 \%$ in 2009 $(\mathrm{p}=0.070)$, and the male students in small towns showed a decreasing trend at a borderline significance level from $2.7 \%$ in 2005 to $4.8 \%$ in 2006 and to $3.8 \%$ in 2009 $(\mathrm{p}=0.066)$.

In 'smoking experience rate before 13 years of age' of the first grade students in middle school, the male students in metropolitan cities showed a decrease at the borderline significance level from $14.7 \%$ in 2005 to $11.6 \%$ in $2009(\mathrm{p}=0.054)$, whereas the female students in rural areas showed a statistically significantly decreasing trend from $12.0 \%$ in 2005 to $6.9 \%$ in 2009 


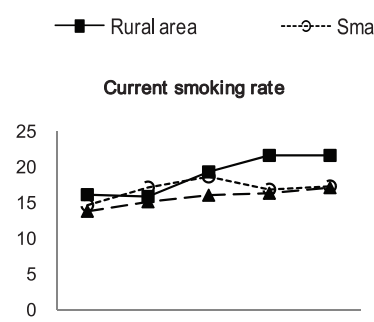

$2005 \quad 20062007 \quad 2008 \quad 2009$

Heavy smokIng rate

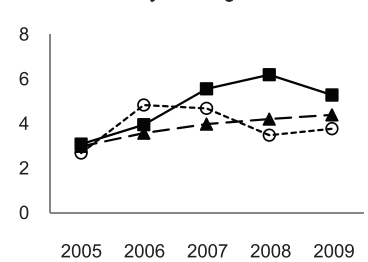

$-\mathbf{-} \cdot \cdot$ Metropolitan city

Frequent smoking rate

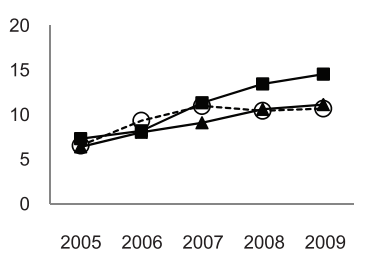

Smoking experience rate before 13 years of age

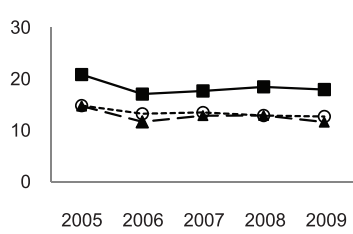

Figure 1. Five year trends of smoking indicators for male by region.

$(\mathrm{p}=0.021)$. The female students in metropolitan cities showed a decreasing trend at a borderline significance level from $10.3 \%$ in 2005 to $8.1 \%$ in $2009(\mathrm{p}=0.067)$.

\section{DISCUSSION}

This study sought to analyze the trend of smoking indicators of adolescents in the most recent 5 years based on rural areas, small towns, and metropolitan cities, which are different in their physical, socio-cultural environment. At the national level, the National Survey on Smoking Status of Middle and High School Students has been conducted by Korean Association of Smoking and Health and Yonsei University's Graduate School of Public Health since 1988. However, the figures from the unstable smoking rates make it difficult to observe a certain pattern, and the sample size is too small for detailed analysis. There are also problems with reliability and weight measuring because the research was commissioned to each participating school. In addition, a health related survey containing the smoking status of adolescents has been conducted as part of the Korea National Health and Nutrition Examination Survey. However, the survey has had a problem, in that the smoking rates were too low because the survey has been conducted by students with their parents accompanied [15]. To identify adolescent health status, Korea Centers for Disease Control and Prevention has been calculating youth health indicators representing Korea by performing KYRBWS since 2005. The KYRBWS stratified the population considering region and school

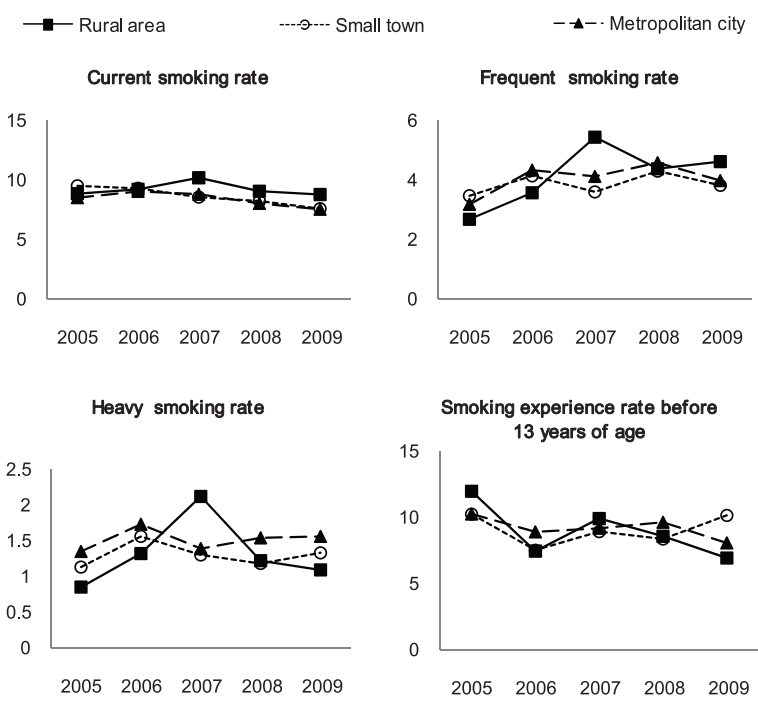

Figure 2. Five year trends of smoking indicators for female by region.

Table 3. Logistic regression coefficients of trend and $\mathrm{p}$-value with adjusted grade

\begin{tabular}{|c|c|c|c|}
\hline & Rural area & Small town & $\begin{array}{l}\text { Metropolitan } \\
\text { city }\end{array}$ \\
\hline \multicolumn{4}{|c|}{ Current smoking rate ${ }^{1}$} \\
\hline Male & $0.068(0.009)$ & $-0.011(0.626)$ & $0.021(0.211)$ \\
\hline Female & $-0.041(0.281)$ & $-0.095(0.001)$ & $-0.073(0.007)$ \\
\hline \multicolumn{4}{|c|}{ Frequent smoking rate ${ }^{2}$} \\
\hline Male & $0.154(<0.001)$ & $0.039(0.192)$ & $0.092(<0.001)$ \\
\hline Female & $0.067(0.239)$ & $-0.040(0.370)$ & $-0.018(0.664)$ \\
\hline \multicolumn{4}{|c|}{ Heavy smoking rate ${ }^{3}$} \\
\hline Male & $0.086(0.070)$ & $-0.065(0.066)$ & $0.030(0.282)$ \\
\hline Female & $-0.021(0.768)$ & $-0.062(0.319)$ & $-0.040(0.451)$ \\
\hline \multicolumn{4}{|c|}{ Smoking experience rate before 13 years of age $^{4}$} \\
\hline Male & $-0.034(0.342)$ & $-0.040(0.142)$ & $-0.045(0.054)$ \\
\hline Female & $-0.112(0.021)$ & $0.007(0.856)$ & $-0.044(0.067)$ \\
\hline
\end{tabular}

${ }^{1}$ Percentage of students who smoked cigarettes on one or more of the past 30 days.

${ }^{2}$ Percentage of students who smoked cigarettes on 20 or more of the past 30 days.

${ }^{3}$ Percentage of students who smoked more than 10 cigarettes per day on the days they smoked during the past 30 days.

${ }^{4}$ Percentage of students who smoked cigarette for the first time before 13 years of age among 1 st grade of middle school students.

(middle school, general high school, and vocational high school) to minimize sampling error, and extracted the sample by applying the proportional allocation method to match the population composition and sample composition. In addition, the survey has a sufficient sample size and its participation rate is also very high because it uses approximately 80000 adolescents each year. Therefore, the KYRBWS can be considered a representative survey of the health status of adolescents in Korea [14].

The results of this study revealed that the smoking indicators of male students in rural areas are in an 
increasing trend. 'Current smoking rate' of the male students in rural areas was significantly increased. While 'smoking rate of more than 20 days a month' showed significantly increasing trend in male students both of rural areas and metropolitan cities, the increasing trend in male students of rural areas was steeper. 'Smoking rate of more than 10 cigarettes a day' of male students in rural areas showed an increasing trend, although it was not statistically significant. However, the questionnaire item for asking 'smoking rate of more than 10 cigarettes a day' changed from 'how many cigarettes have you smoked on average on the day you smoked during the past 30 days' in the period between 2005 and 2008 to 'how many cigarettes have you smoked a day on average during the past 30 days' in 2009. Therefore, the 'smoking rate of more than 10 cigarettes a day' in 2009 was underestimated compared to the rate using previous questionnaire item. Given this change, even though the 'smoking rate of more than 10 cigarettes a day' of male students in rural areas showed a borderline significance level with the $\mathrm{p}$ value of 0.070 , it was most likely to increase significantly. Therefore, it is thought that the students in rural areas showed a statistically significant increasing trend in 'current smoking', 'smoking rate of more than 20 days a month', and 'smoking rate of more than 10 cigarettes a day'. In addition, the 'smoking experience rate before 13 years of age' of the first grade students of middle school was higher in rural areas than urban areas, although the male students did not show any statistically significant trend.

In the case of female students, 'current smoking rate' showed a significant decrease in both small towns and metropolitan cities, but the 'smoking experience rate before 13 years of age' showed a significantly decreasing trend in rural areas, indicating that the smoking indicators did not show any consistent trend by region. This result suggests that even similar social environment may affect differently on male and female students. Several studies found that the behaviors of male and female students on smoking vary [16-21]. Mistry et al. [18] said that male students have tendency to relieve stress by smoking or using drugs, while female students tend to have inappropriate eating habits or not to go out. In addition, Lee [22] found that male students have a tendency to think the smoking friends and the peoples smoking in TV or magazines to be cool, compared to female students. Therefore, it will be necessary for the future studies analyzing smoking status of adolescent and related factors to stratify it into male and female students.

Most studies on the adolescent smoking in Korea have conducted with limitations, focusing on a single area, either urban or rural region $[20,21,23]$, and there are not many studies comparing the smoking status by region. Shin et al. [9] found that the smoking rate of students in rural areas were significantly higher than that of urban areas. Park [10] reported that the smoking experience rate and smoking experience rate before 13 years of age in rural areas were higher than those of urban areas. Studies of foreign countries indicated that the result varied depending on the countries where the studies were conducted $[11-13,24,25]$. It is thought that these different results may be due to the fact that each country has the social and cultural difference, and the smoking policies are different in their strength or direction.

The results of this study, which show the increasing trend of smoking indicators in rural areas, can be estimated through the factors that are related with adolescent smoking. As a first factor, stresses can affect the adolescent smoking. Among others, the socioeconomic stress, or the poor economic conditions and living environment stress can influence adolescent smoking [26]. Yu et al. [23] reported that if the adolescents are in poorer economic condition, the smoking rate is higher, and the adolescents of broken families had higher smoking rate than those of normal families. In the early 1960s, and from 1974 until the end of the 1980s, farm income was higher than urban worker income level. However, since the income of urban household has exceeded the farm income in 1989, its disparity has been expanding. Particularly after the financial crisis in 1997, the average income gap has continuously expanded, putting the farm income at $80 \%$ of urban household income in 2000 and $73 \%$ in 2002 [8]. In 2008, the average farm income was 30.52 million won, making the ratio of farm income to urban household income $65.3 \%$, indicating that the disparity between urban and rural areas has been widening [27]. It was found that the socioeconomic condition, family wealth index, and educational level of parents also poorer in the students of rural areas compared to the urban areas [28]. Therefore, the increasing trend of adolescent smoking rate in rural areas can be largely attributed to the rural and urban disparities in socioeconomic status.

Second, the parent's smoking status can largely influence on adolescent smoking. Several studies in other countries reported that parental smoking can be related to adolescent smoking [29-31], and the studies in Korea also found that the smoking rate of adolescents having smoking parent is higher $[20,21]$. According to the smoking rate of adults over the age of 20 released by Statistics Korea, Dong area, which is part of urban area, 
showed a decreasing trend from $29.3 \%$ in 2003 to $27.5 \%$ in 2006 and to $25.8 \%$ in 2008. However, Eup-Myeon area, which is part of rural area, showed $29.3 \%$ in 2003, $26.5 \%$ in 2006 , and $28.2 \%$ in 2008 , inferring that the smoking rate of the parents in rural areas is relatively increasing compared to that of urban areas [32-34]. In addition, Lee and Park [35] reported that $10 \%$ of motivation for smoking of children in rural areas is explained by the stimulus by adults including father, and $18.6 \%$ was explained by adults including father for the source of cigarettes. This indicates that the rural areas are more generous or have weaker regulation for adolescent smoking, and the adolescent smoking is largely affected by the attitude of parents or the adults toward smoking.

Third, the smoking friends also affect adolescent smoking [23]. Lee's study found that the adolescents having friends who smoke are likely to smoke 14.8 times more than the adolescents who do not have friends who smoke [20]. According to the study of rural adolescents, while $41.3 \%$ of the students in urban areas are taking extra class for more than three hours after school, $61.9 \%$ and $67.2 \%$ of the students in the suburban and rural areas, respectively, did not take any extra class. It was also found that the adolescents who are reading or studying in rural areas are less than those in urban areas. Adolescents in rural areas have less time for hobby activities after school, and the proportion of time spending with friends for more than 3 hours is higher in urban areas [36]. While the students in urban areas spend their daily time in private institutions or unsupervised night learning after school, the students in rural areas have plenty of free time and fewer benefits of education, culture and leisure facilities. Therefore, they are more likely to have chances for smoking and drinking alcohol with their friends. In addition, it is thought that since they have a lot of time to spend with friends compared to the students in urban areas, they are more likely to be influenced by their friends. Therefore, as the number of adolescents who smoke increase, more adolescents follow their smoking friends, and thus, the smoking rate is more likely to rise steeply.

Finally, the results of this study suggest that selfesteem of adolescents is related to smoking. Choi et al. [21] reported that the adolescents with lower self-esteem had more experience of smoking. Park [37] also reported that smoking of high school students is associated with self-esteem. Meanwhile, studies on the adolescents in rural areas found that the adolescents in rural areas view themselves more negatively than the adolescents in urban areas [36], indicating that the negative selfconsciousness of adolescents in rural areas also affect their smoking behaviors as a psychological factor.

The limitations of this study are as follows. It divided the areas based on administrative districts, thus did not reflect the exact nature of regions. In the case of small towns, there are many urban-rural complex cities. However, the study did not consider the difference between Eup-Myeon area which has the similar nature with rural area and Dong area, which has the nature of city. In addition, as the first period sample (2005 - 2007) changed into the second period sample (2008 - 2009), there was a problem of analyzing the exact trend due to the change in sample frame. Furthermore, because the KYRBWS is self-administered survey, there is a limitation of accuracy of the survey.

Despite these limitations, this study has significance because it is the only study on the trend of adolescent smoking by region in Korea using the national level of sample. Moreover, it has value because it is a study evaluating the trend through statistical analysis. Given that the gap of health status has widened as the socioeconomic and cultural disparity between urban and rural areas is currently worsening, the study result that the smoking indicators in rural areas is on the rise has significant implication. Based on the results of this study, further studies on a causal relationship between smoking in rural areas and the independent variables including socio-economic factors, which can affect adolescent smoking are necessary.

Since smoking in adolescence often precedes other drug abuse, such as alcohol or drug [38], it not only impacts the personal level of physical health, but also causes mental and social damages. In addition, because the adolescents are our future and will be the leaders of the society, the loss of the entire nation from adolescent smoking will be tremendous. Therefore, the prevention and cessation of smoking project cannot be overestimated.

The results of this study showed that the smoking indicators of male students in rural areas have been increasing trend for the last 5 years. It is believed that a focus should be placed on reducing the smoking rate of students in rural areas when implementing the project of smoking prevention and cessation. In addition, it is necessary to take into account the regional conditions when evaluating adolescent smoking prevention and cessation, and to establish a policy for smoking prevention and cessation which is efficient and applicable depending on the characteristics of regions. 


\section{CONFLICT OF INTEREST}

The authors have no conflicts of interest with the material presented in this paper.

\section{REFERENCES}

1. World Health Organization. WHO report on the global tobacco epidemic, 2009: implementing smoke-free environments. Geneva: World Health Organization; 2009.

2. Holmen TL, Barrett-Connor E, Holmen J, Bjermer L. Health problems in teenage daily smokers versus nonsmokers, Norway, 1995-1997: the Nord-Trondelag Health Study. Am J Epidemiol 2000; 151(2): 148-155.

3. Wiencke JK, Kelsey KT. Teen smoking, field cancerization, and a "critical period" hypothesis for lung cancer susceptibility. Environ Health Perspect 2002; 110(6): 555558.

4. Camenga DR, Klein JD, Roy J. The changing risk profile of the American adolescent smoker: implications for prevention programs and tobacco interventions. $J$ Adolesc Health 2006; 39(1): 120.e1-120.e10.

5. Fergusson DM, Horwood LJ. Transitions to cigarette smoking during adolescence. Addict Behav 1995; 20(5): 627-642.

6. Kim DS, Lee SS. Ecological environments and regional differences in the structure of cause of death. Korean $J$ Sociol 2004; 38(4): 133-158. (Korean)

7. Robert SA. Community-level socioeconomic status effects on adult health. J Health Soc Behav 1998; 39(1): 18-37.

8. Lee DP, Park SH, Kim TY, Seong JI, Shin EJ, Kim JH, et al. A study on the releasing income gap between urban and rural areas through the balanced regional development strategies. Seoul: Korea Rural Economic Institute; 2004. (Korean)

9. Shin DH, Kim DH, Kim YH, Yoon YJ, Kwon CH. The smoking rate and knowledge of smoking hazards for male high school students in urban and rural areas. J Korean Acad Fam Med 1996; 17(10): 877-883. (Korean)

10. Park SW. Health behaviors among adolescents in the rural area in Korea. J Agric Med Community Health 2009; 34(2): 202-213. (Korean)

11. Lutfiyya MN, Shah KK, Johnson M, Bales RW, Cha I, McGrath C, et al. Adolescent daily cigarette smoking: is rural residency a risk factor? Rural Remote Health 2008; 8(1): 875.

12. Cronk CE, Sarvela PD. Alcohol, tobacco, and other drug use among rural/small town and urban youth: a secondary analysis of the monitoring the future data set. Am J Public Health 1997; 87(5): 760-764.

13. Sarvela PD, Cronk CE, Isberner FR. A secondary analysis of smoking among rural and urban youth using the MTF data set. J Sch Health 1997; 67(9): 372-375.
14. Korea Centers for Disease Control and Prevention. Report on the Korea Youth Risk Behavior Web-based Survey, 2009. Seoul: Korea Centers for Disease Control and Prevention; 2010. (Korean)

15. Korea Centers for Disease Control and Prevention. Smoking behaviors among korean adolescents: the results of Youth Risk Behavior Web-based Survey 2005-2007. Public Health Wkly Rep 2008; 1(36): 601-608. (Korean)

16. Mistry R, McCarthy WJ, Yancey AK, Lu Y, Patel M. Resilience and patterns of health risk behaviors in California adolescents. Prev Med 2009; 48(3): 291-297.

17. Pitel L, Geckova AM, Vandijk JP, Reijneveld SA. Degree of urbanization and gender differences in substance use among Slovak adolescents. Int J Public Health DOI: 10.1007/s00038-010-0219-3.

18. Mistry R, McCarthy WJ, de Vogli R, Crespi CM, Wu Q, Patel M. Adolescent smoking risk increases with wider income gaps between rich and poor. Health Place 2011; 17(1): 222-229.

19. de Meer G, Crone MR, Reijneveld SA. Gender differences in the association between pre-adolescent smoking initiation and emotional or behavioural problems. BMC Public Health 2010; 10: 615.

20. Lee CY, Margaret JS, Cho WJ, Bae SH, Lee KH, Ham $\mathrm{OK}$, et al. A study of adolescent smoking related factors in the Seoul area. J Korean Community Nurs 2004; 15(1): 95101. (Korean)

21. Choi WH, Je MS, Lee SS. Factors related to smoking behavior among high school students. J Korean Acad Public Health Nurs 2010; 24(2): 226-236. (Korean)

22. Lee LI. A study on smoking status of adolescent and its related factors in a rural area [dissertation]. Daejeon: Konyang University; 2005. (Korean)

23. Yu BK, Oh YJ, Lee JC, Lee KH, Min JH, Park SH. A study of adolescent smoking and drinking in Korea. Korean J Pediatr 2009; 52(4): 422-428. (Korean)

24. Völzke H, Neuhauser H, Moebus S, Baumert J, Berger K, Stang A, et al. Urban-rural disparities in smoking behaviour in Germany. BMC Public Health 2006; 6: 146.

25. Duelberg SI. Preventive health behavior among black and white women in urban and rural areas. Soc Sci Med 1992; 34(2): 191-198.

26. Schepis TS, Rao U. Epidemiology and etiology of adolescent smoking. Curr Opin Pediatr 2005; 17(5): $607-$ 612.

27. Statistics Korea. 2008 farm household economy survey report. Daejeon: Statistics Korea; 2009. (Korean)

28. Park E. A comparative study of youth health risk behaviors by region: focused on metropolitan areas, medium sized and small city areas, and rural areas. J Korean Acad Nurs 2010; 40(1): 14-23. (Korean)

29. Barman SK, Pulkkinen L, Kaprio J, Rose RJ. Inattentiveness, parental smoking and adolescent smoking initiation. Addiction 2004; 99(8): 1049-1061.

30. Järvelaid M. Adolescent tobacco smoking and associated 
psychosocial health risk factors. Scand J Prim Health Care 2004; 22(1): 50-53.

31. Taylor JE, Conard MW, Koetting O’Byrne K, Haddock CK, Poston WS. Saturation of tobacco smoking models and risk of alcohol and tobacco use among adolescents. $J$ Adolesc Health 2004; 35(3): 190-196.

32. Statistics Korea. Report on the social survey. Daejeon: Statistics Korea; 2008. (Korean)

33. Statistics Korea. Report on the social survey. Daejeon: Statistics Korea; 2006. (Korean)

34. Statistics Korea. Report on the social survey. Daejeon: Statistics Korea; 2003. (Korean)

35. Lee SW, Park SW. Smoking behaviors and associated factors among elementary school students in a rural area. $J$
Korean Soc Matern Child Health 2005; 9(1): 73-84. (Korean)

36. Kim SS, Kim KJ, Jeon KS. A study on rural adolescent issues and improvement of 21st century. Seoul: National Youth Policy Institute; 2000. (Korean)

37. Park NH. Gender differences in the association between psycho-social factors and smoking, drinking in adolescents. J Korean Soc Health Educ Promot 2005; 22(4): 123-136. (Korean)

38. Botvin GJ, Griffin KW, Diaz T, Scheier LM, Williams C, Epstein JA. Preventing illicit drug use in adolescents: longterm follow-up data from a randomized control trial of a school population. Addict Behav 2000; 25(5): 769-774. 